\title{
The new challenges of end-of-life tyres management systems: A Spanish case study
}

\author{
Ángel Uruburu Eva Ponce-Cueto José Ramón Cobo-Benita Joaquín Ordieres-Meré
}

\begin{abstract}
A B S T R A C T
Directive 2008/98/EC released by the European Union represents a significant step forward in all relevant aspects of waste management. Under the already established, extended produced responsibility (EPR) principle, new policies have been enunciated to continuously achieve better overall environmental performance of key products throughout their life phases. This paper discusses how the directive is being articulated in Spain by the main integrated management system (IMS) for end-of-life (EOL) tyres since its creation in 2006. Focusing on the IMS technological, economic and legal aspects, the study provides a global perspective and evaluation of how the IMS is facing the current issues to resolve, the new challenges that have appeared and the management vision for the coming years.
\end{abstract}

\section{Introduction}

A literature review revealed that the majority of articles that are related to end-of-life (EOL) tyres, when considering the new European Directive 2008/98/EC (European Union, 2008), focus mainly on technical solutions (Aiello et al., 2009; Aylón et al., 2010; Bernardo et al., 2010; Donatelli et al., 2010; Sang Son et al., 2011; Shulman, 2011; Singh et al., 2009). With regard to the application of this new directive, other articles are based on an assessment of waste management technologies according to the waste hierarchy identified in this Directive (Generowicz et al., 2011), or alternative treatment technologies that have been evaluated on their cost aspects, product utilization and compatibility with the EU waste framework that was proposed in the mentioned directive (Donatello et al., 2010; Grosso et al., 2010).

At a regional level, there are several analyses that are based on case studies of waste management. They focus primarily on: municipal solid waste (Björklund and Finnveden, 2007; Economopoulos, 2010; Gamze Turan et al., 2009; Larsen et al., 2010; Purcell and Magette, 2010), medical waste (Marinković et al., 2008), construction waste (Sang Son et al., 2011), industrial waste (Gunning et al., 2010), used batteries (Ponce-Cueto et al., 2011), electrical and electronic equipment waste (Achillas et al., 2010) or end-of-life vehicles (Santini et al., 2011).

In this context, it may be noted that the existing information about EOL tyres management issues is somewhat limited. While there are few articles that are specifically oriented to IMS organiza- tional aspects under the new regulatory framework, other articles are based on the application of the previous Directive 2006/12/EC (e.g. Ferrão et al., 2008; Milanez and Bührs, 2009). Therefore, in regard to EOL tyres management, we believe that an in-depth study of the scope, main new aspects, objectives and future targets under the new European legislation network needs to be conducted in order to provide an updated, more precise and clearer framework for analysis.

\section{Objectives and methodology}

The main goal of this paper is to analyse the impact of implementation of EU Waste Framework Directive 2008/98 for EOL tyres. For this purpose, the reverse supply chain for collecting, recovering, and treating EOL tyres will be characterized in the Spanish context and in comparison to other representative European IMS. Finally, the main challenges and improvement opportunities of this system will be identified according to the current EU waste framework proposed in Directive 2008/98.

Within this general objective, the potential markets, the implementation options for new applications, the degree of plans development and other relevant aspects have been also taken into account.

In regard to methodology, this research is based mainly on the inductive approach principles of case study research (Eisenhardt, 1989; Ellram, 1996) that is supported by historical data series analysis. To build the case, the Spanish integrated management system (IMS), SIGNUS has been selected. This has been based on three criteria: (a) local tyre market dimension, the fifth in EU27 by EOL annual tyre volume generated (ETRMA, 2011) and thus one of the largest in Europe (b) outstanding achievements of the IMS that 
have been recognized nationally and internationally, such as an IMS reference in regards to rapid progress within the Producer Responsibility Model (WBCSD, 2010) and (c) previous professional experience by one of the authors in the main Spanish IMS, as a participant (representing Bridgestone Spain) in various task forces during the creation and early years of the organization. In addition, the qualitative discussion and conclusions of this paper have been obtained through semi-structured interviews with a group of experts from SIGNUS, who have contributed significantly to the results of this study.

The paper is organised as follows: Section 3 emphasizes the main aspects of the current environmental legislation framework, focusing on a comparison of the new variations and the previous one. Section 4 describes the Spanish IMS case-study, including the collection, EOL recovery options, innovative applications, new national Prevention Plan 2010-2013, communication activities and research and development projects (R\&D). Section 5 provides a discussion based on the quantitative and qualitative results. Finally, the conclusions are summarized in Section 6.

\section{Environmental legislation framework}

In this section we draw attention to the main relevant aspects and new articles apparent in a comparison of the current Directive 2008/98/EC and Directive 2006/12/EC on waste management that affects EOL tyres. Table 1 summarizes these relevant aspects.

Firstly, one of the most important points was established in article 4 of Directive 2008/98/EC, where it described the waste hierarchy to consider and prioritize: prevention, preparing for reuse, recycling, other recovery (e.g., energy recovery), and disposal. Then, member states shall take measures to encourage the options that deliver the best overall environmental outcome. In particular, those measures that affect the management of EOL tyres, due to different waste hierarchy are possible for EOL tyres. These include reuse (including tyre retreading), recycling or energy recovery.

The new Directive also includes the "end-of-waste status" for several wastes such as paper, glass, metal, tyres and textiles. According to Article 6, tyres shall cease to be waste when they comply with specific criteria developed in the Directive.

Another highlight of this Directive on waste is Article 8, which refers to the more specific definition of "extended producer responsibility". On this matter, it states that Member States may take legislative or non-legislative measures to ensure that the producer of the product has extended producer responsibility. In addition, Member States may take appropriate measures to encourage the design of products in order to reduce their environmental impacts. In particular, tyres producers are working on ecodesign aspects in order to reduce the environmental impact of EOL tyres (see Table 5).

Table 1

Main relevant aspects in a comparison of Directive 2008/98/EC and Directive 2006/ $12 / \mathrm{EC}$.

\begin{tabular}{ll}
\hline Directive & Main relevant aspect \\
\hline $2008 / 98 / \mathrm{EC}$ & Waste hierarchy: prevention, preparation for reuse, \\
& recycling, other recovery, and disposal \\
End-of-waste status for several wastes, such as \\
paper, glass, metal, tyres and textiles \\
Need for prevention of waste \\
Encouraging the design of products to reduce their \\
environmental impacts \\
Cost of the WM share by the producer of the \\
product that created the waste and the distributors \\
of the product \\
Cost of WM by the original waste producer or by the \\
current or previous waste holders
\end{tabular}

Table 2

European and Spanish EOL tyre regulations.

\begin{tabular}{lll}
\hline Year & Code & Topic \\
\hline 2011 & Law $22 / 2011$ & Spanish law of wastes and polluted soils \\
2008 & $2008 / 98 / \mathrm{EC}$ & On waste management \\
2006 & $2006 / 12 / \mathrm{EC}$ & On waste management \\
2005 & RD $1619 / 2005$ & Management of EOL tyres \\
2000 & $2000 / 53 / \mathrm{CE}$ & Management of EOL Vehicles \\
\hline
\end{tabular}

Another major development is the need for prevention of waste. By the end of 2011, reports should include the evolution of waste generation, the scope of waste generation (including the formulation of a product ecodesign policy) and the formulation of an action plan for further support measures. By the end of 2014, the report should include the establishment of waste prevention and decoupling objectives for 2020 .

As in Directive 2006/12/EC according to the polluter-pays principle, the cost of waste management shall be borne by the original waste producer or by the current or previous waste holders. The novelty of the recent directive is that the costs of waste management are to be borne partly or wholly by the producer of the product from which the waste came and the distributors of the product may share these costs. This is a relevant aspect of the new directive that could affect the operation of the integrated management system of EOL tyres, making the financing of the waste management system more complex since more actors would be involved. Additionally, the EPR principle requires that every distributor that resells tyres to other dealers automatically becomes a producer and then must assume the corresponding responsibilities.

In the Spanish context, the relevant legislation on the management of EOL tyres is the Royal Decree 1619/2005. This legislation extends the responsibility to tyre producers. Disposal targets require that the producers at least accomplish the environmental objectives that have been established in the corresponding $\mathrm{Na}$ tional Plan of EOL tyres (PNNFU, 2001). Law 22/2011 is the Spanish transposition of Directive 2008/98 on waste management, and repeal the previous law $10 / 1998$ on wastes. The following Table 2 summarises the European and Spanish legislation regarding EOL tyres:

\section{The management system for EOL tyres in Spain}

In the next sections we describe all relevant aspects of the management system for EOL tyres in Spain. First, the different European models and the option selected in Spain will be characterized. Secondly, various EOL tyre-recovering options are analysed: reuse/retreading, recycling and energy recovery. Finally, innovative initiatives to meet new regulations are presented. As mentioned above, the main purpose is to provide an overall perspective of how the IMS is performing according to new European and local legislation requirements, and then provide actual figures and their evolution since the year 2006 and specific benchmarking with other key European IMS.

\subsection{European EOL tyre management models}

According to Spicer and Johnson (2004), several models can be adopted for EOL product management. Today there are three different systems within Europe: (a) producer responsibility, (b) tax system and (c) free market system. The first model is articulated in each country under the corresponding legal framework, which usually led to the establishment of a not-for-profit company financed by tyre producers and intended to manage collection and recovery of end-of-life tyres by the most economical solutions. In 
addition, these companies are able to develop a high-level knowledge of technologies and build additional R\&D capacities and guarantee transparency of operating costs through a visible contribution, clearly indicated on the invoices for services.

Under the tax system model, the government of each country is responsible for the collection, recovery and recycling of EOL tyres. It is financed by a tax that is levied on EOL producers and subsequently passed onto the customer. This is an intermediate system whereby the producers pay a tax to the State, which is responsible for the overall organisation and remunerates the operators in the recovery chain.

Under the free market system, national legislation sets the objectives to be met, but does not designate who are responsible. In this way, all the operators in the recovery chain contract under free market conditions and act in compliance with legislation. This may be backed up by voluntary cooperation between companies to promote best practices.

Extended Producer Responsibility (EPR) appears to be the most suitable and robust system for addressing and resolving EOL tyres arising, in a sustainable manner over the long term and achieving a $100 \%$ recovery rate in the most economical way (ETRMA, 2011). In general, tyre manufacturers have demonstrated a clear preference for this system and have exercised determination and commitment in taking this route. In 2010, the EPR systems network includes 15 countries (Belgium, Estonia, Finland, France, Greece, Hungary, the Netherlands, Norway, Poland, Portugal, Romania, Slovenia, Spain, Sweden and Turkey), and other EU Member States (e.g., Italy) are set to follow in the near future.

In the Spanish case, the main tyre producers have opted to set up a non-profit organization named SIGNUS that assures an environmentally-sound management of EOL tyres in compliance with extended producer responsibility (EPR) legislation.

It is interesting to note that, although Directive 2008/98/EC considers the possibility of sharing the financing cost of the overall system among the producers and distributors, that is not the case in the Spanish system, which is financed by end users through the eco-fee tax. Thus, producers pass all the costs along the distribution chain to consumers, who pay a tax predetermined by the IMS on every new tyre placed in the market. The same finance system can be found in the neighbours' IMSs, such as Aliapur in France, Valorpneu in Portugal and Ecopneus in Italy, all of which operate under EPR model characteristics.

\subsection{Integrated management system: SIGNUS}

In Spain, there are two IMSs that are structured under the EPR scheme: SIGNUS and TNU. The first is responsible for approximately $90 \%$ of the EOL tyres generated throughout Spain, while the second manages the remaining $10 \%$. For the purpose of this study only SIGNUS case will be considered. Apart from the differences in the volumes managed, TNU's founders and members are specialized and very much focused on the importation of tyres, a niche market in Spain, while activities concerning EOL tyres are represented only to a limited extent.

SIGNUS was created in 2006 after issuance of Royal Decree 1619/ 2005 , which required producers to guarantee the correct management and treatment of all tyres made available for sale nationally.

It is interesting to note that, in the preparation and development of the decree, tyre manufacturers participated proactively with other key stakeholders, such as regional administrations, distributors, and tyre dealers in what can be understood to be a new and global socially responsible approach to this specific environmental issue.

The founding members were Bridgestone, Continental, Goodyear Michelin and Pirelli, which control around $90 \%$ of the tyre replacement market.

\subsubsection{EOL tyres production vs. collection}

Fig. 1 compares the growth since 2006 of collected tyres vs. tyres placed-on-the market. In 2010, SIGNUS collected 195,480 tonnes from all Spanish territory, an increase of $5.1 \%$ over 2009 . By the end of 2010, a total of 112,744 requests to collect used tyres had been received from 32,276 generation points in 3652 towns and villages in Spain's 17 regions and 2 autonomous cities. All requests were met, in strict compliance with the universality principle.

The imbalance between the number of tyres collected and those placed on the market ( $7 \%$ in 2010), continues to be of major concern to the Spanish IMS, representing an additional cost of 13.7 million euro since 2006, which SIGNUS members bear voluntarily to prevent any negative environmental impact.

According to IMS top management, the EOL tyres stock accumulated before the start of the operations has been correctly processed and is no longer a concern. What is increasingly becoming a very serious problem is the fraud that is committed in the form of undeclared sales (for instance tyres imported through the internet) by those who fail to meet their obligations. This situation has negative consequences not just for the sector itself, but for society as a whole, since end users incur this management cost when purchasing new tyres and the only beneficiaries are the fraudsters. The same concern can be found in other European IMS reports (Aliapur, 2011).

Two types of measures should be implemented to overcome this situation. On one side, public administration should take actions based on control and fraud prosecution that are already included in the new Spanish Waste and Contaminated Soils Law (LRSC). On the other, all market players (distributors, garages, waste-managers, associations IMS) need to become more actively involved, which would greatly aid the fight against this fraudulent practice.

\subsubsection{Producers and generators of EOL tyres}

A producer is an individual or legal entity that manufactures tyres for the Spanish replacement tyre market or imports or introduces tyres for the first time to it.

A generator is an individual or legal entity that, as a result of its commercial activities in its facilities, produces directly or indirectly end-of-life tyres. More precisely, it usually refers to every garage or outlet where new, used or retread tyres are mounted in substitution or other new ones, which have been previously acquired from a manufacturer, distributor or importer, namely producers.

Evolutions since 2006 are displayed in Figs. 2 and 3. A number (62) of new producers joined SIGNUS during, 2010. Many of them are Internet business-based tyre dealers who are selling in Spain. A total of 211 producers have joined SIGNUS to date. In regard to generators, 2221 new collection points, most of which are garages, were accredited to SIGNUS during the year. At December 31st, the total number of generators stood at 32,276 , covering the entire country.

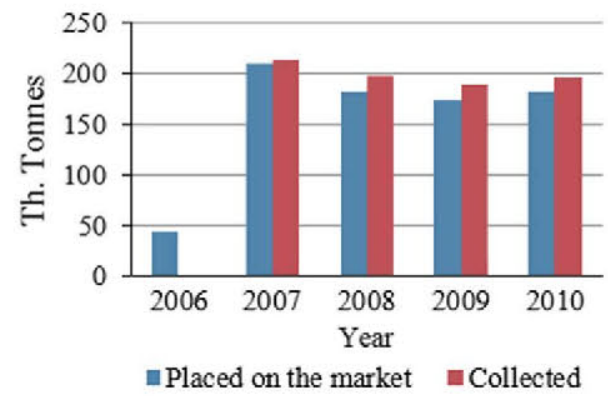

Fig. 1. Collected tyres vs. tyres placed on the market. 


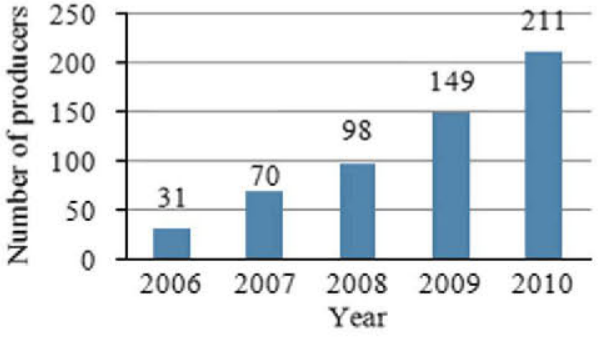

Fig. 2. Number of producers joined SIGNUS.

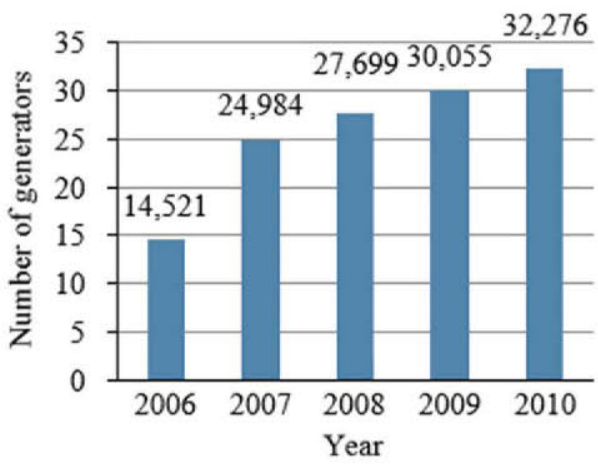

Fig. 3. Number of generators.

\subsubsection{Key collection figures}

Following the universality principle, SIGNUS is committed to attending to every collection request from its members within the following 10 days, irrespective of the location of the point of sale and the number of EOL tyres. Yet, in 2010, the average collection time was 6.0 days following receipt of the request and $92 \%$ of the almost 113 thousands requests were met within the stipulated deadline.

Table 3 shows the key figures of the global activity in Spain for 2011, compared to those for the corresponding IMS neighbours in France, Portugal and Italy, all of which operate under the EPR model (Italy changed to this system in 2011).

Collection and transportation costs represents a significant portion of the total IMS turnovers (from $41 \%$ in Portugal up to $54.4 \%$ in Spain). As for the volumes collected and considering the population of each country, the ratio in kg per person in Portugal and Italy are very high compared to those in France and Spain. One explanation may be the stockpile abatement efforts taken by the two first mentioned IMSs, an issue that seems to have been solved in the second case.

Nevertheless, the relatively higher number of collection points in Spain (5 times that in Portugal, 1.75 times that in Italy) and the value of the indicator tonnes collected per point of generation (5.16, the lowest among the four IMSs considered), reflects the need for further countermeasures to improve the overall efficiency of the system.

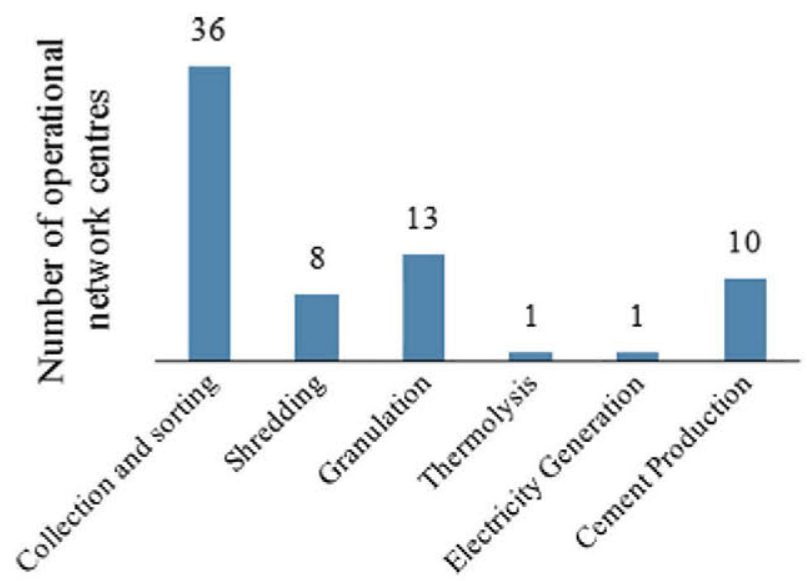

Fig. 4. SIGNUS operational network centres.

In our interviews with the Spanish IMS managers, they remarked that this issue requires maximum priority within its strategic plan. In this sense, they pointed to the current development of a new collection model that better reflects the needs of EOL tyre generators more effectively.

Anyway, since 2007 to the present, both the French and the Spanish model have been able to reduce the passenger car ecofee from $1.75 €$ and $1.98 €$ to $1.5 €$ and $1.57 €$ respectively, (14\% and $21 \%)$ while the new Portuguese fee for the rest of 2012 reflects an increase of $20 \%$ (1.20€ vs $1.00 €$ ).

In fact, the Spanish model has been recognized as a quick development as it started in 2006 and was able to claim $100 \%$ of EOL tyre management by 2008 , continuing at the same throughput to the present (WBCSD, 2010).

To conclude, we found that further coordination between European tyre IMSs would be necessary in order to carry out operational benchmarking that would enable each country to implement best practices.

\subsubsection{Operational network}

SIGNUS has consolidated the activities of its operational network, which connects various firms engaged in EOL tyre management, treatment or uses for specific applications.

The logistic network includes 36 collection and sorting centres, 8 shredding and 13 granulation facilities, and 12 treatment facilities. There were 69 different facilities in 2010, as per Fig. 4 below.

\subsection{EOL tyres recovery options}

The actors defined in the section above with the corresponding transport companies manage the EOL tyres volumes included in Table 4. According to the different recovery options for EOL tyres, there is a first, basic classification. It consists of reuse, recycling (material recovery) and energy recovery options.

A total of 192,070 tonnes of EOL tyres were managed in 2010, $9 \%$ of which were reused in the second-hand or retread market.

Table 3

Collection key figures in 2011.

\begin{tabular}{|c|c|c|c|c|c|c|c|c|}
\hline Country & $\begin{array}{l}\text { No points of } \\
\text { generation }\end{array}$ & $\begin{array}{l}\text { Collection } \\
\left(T_{m}\right)\end{array}$ & $\begin{array}{l}\text { Collection/point } \\
\left(T_{m}\right)\end{array}$ & $\begin{array}{l}\text { Collection cost } \\
(\text { million } €)\end{array}$ & $\begin{array}{l}\text { Total IMS costs } \\
\text { (million } € \text { ) }\end{array}$ & $\begin{array}{l}\% \text { Collection vs. } \\
\text { total }\end{array}$ & $\begin{array}{l}\text { EOL tyres } \mathrm{kg} / \\
\text { person }\end{array}$ & $\begin{array}{l}\text { Passenger car eco- } \\
\text { fee }(€)\end{array}$ \\
\hline Spain & 34357 & 177234 & 5.16 & 20.4 & 37.5 & 54.4 & 4.96 & 1.57 \\
\hline France & 44000 & 297699 & 6.77 & 25.1 & 48.6 & 51.6 & 4.62 & 1.50 \\
\hline Portugal & 4932 & 90373 & 18.32 & 3.7 & 9.1 & 41.0 & 8.50 & 1.00 \\
\hline Italy & 20000 & 371000 & 18.55 & n.a. & 28.1 & n.a. & 6.10 & 2.80 \\
\hline
\end{tabular}


Table 4

End-of-life tyre processed volume evolution.

\begin{tabular}{|c|c|c|c|c|c|c|c|c|c|c|c|c|}
\hline & \multicolumn{2}{|l|}{2006} & \multicolumn{2}{|l|}{2007} & \multicolumn{2}{|l|}{2008} & \multicolumn{2}{|l|}{2009} & \multicolumn{2}{|l|}{2010} & \multicolumn{2}{|c|}{$2006-2010$} \\
\hline & $T_{m}$ & $\%$ & $T_{m}$ & $\%$ & $T_{m}$ & $\%$ & $T_{m}$ & $\%$ & $T_{m}$ & $\%$ & $T_{m}$ & $\%$ \\
\hline Retread & 1523 & 81 & 8421 & 5 & 13309 & 6 & 10928 & 6 & 11416 & 6 & 45597 & 6 \\
\hline 2nd Hand & 366 & 19 & 3046 & 2 & 5762 & 3 & 5839 & 3 & 5843 & 3 & 20856 & 3 \\
\hline Total reuse & 1889 & 100 & 11467 & 7 & 19071 & 8 & 16767 & 9 & 17259 & 9 & 66453 & 9 \\
\hline Rubber granulate and recycle led steel & & 0 & 114126 & 73 & 108184 & 47 & 99379 & 53 & 94789 & 49 & 416478 & 54 \\
\hline Civil engineering & & 0 & 8897 & 6 & 18804 & 8 & 710 & 0 & 1781 & 1 & 30192 & 4 \\
\hline Others & & 0 & 256 & 0 & 5903 & 3 & 141 & 0 & 644 & 0 & 6944 & 1 \\
\hline Total recycling and recovery & 0 & 0 & 123279 & 79 & 132891 & 58 & 100230 & 54 & 97214 & 51 & 453614 & 59 \\
\hline Thermolysis & 0 & 0 & 0 & 0 & 0 & 0 & 0 & 0 & 1384 & 1 & 1384 & 0 \\
\hline Electricity production & & 0 & 2720 & 2 & 3255 & 1 & 2806 & 1 & 2942 & 2 & 11723 & 2 \\
\hline Cement manufacture & & 0 & 19239 & 12 & 75190 & 33 & 67394 & 36 & 73271 & 38 & 235094 & 31 \\
\hline Total energy recovery & 0 & 0 & 21959 & 14 & 78445 & 34 & 70200 & 38 & 77597 & 40 & 248201 & 32 \\
\hline Total EOL processed tyres & 1889 & 100 & 156705 & 100 & 230407 & 100 & 187197 & 100 & 192070 & 100 & 768268 & 100 \\
\hline
\end{tabular}

Table 5

Prevention areas and measures.

\begin{tabular}{|c|c|c|c|}
\hline & $\begin{array}{l}\text { Design, } \\
\text { production }\end{array}$ & Distribution & Consumption and use \\
\hline \multicolumn{4}{|l|}{ 1. Mechanisms to extend the life of tyres } \\
\hline Changes in tyre composition and/or design to increase mileage performance & $\times$ & & \\
\hline Fostering, developing and promoting processes and best practices for good tyre care & $\times$ & $x$ & $x$ \\
\hline \multicolumn{4}{|l|}{ 2. Mechanisms to facilitate reuse } \\
\hline Changes in tyre composition and/or design to facilitate regrooving and retreading & $x$ & & \\
\hline Dissemination and promotion of processes to facilitate regrooving and/or retreading & & $x$ & $\times$ \\
\hline Encouragement of processes to strengthen the partly worn tyre market in a responsible manner & & $x$ & $x$ \\
\hline \multicolumn{4}{|l|}{ 3. Mechanisms to facilitate recycling and other forms of recovery of end-of-life tyres } \\
\hline$r+d+i$ in tyre components/design to facilitate recycling and recovery & $x$ & $x$ & \\
\hline Dissemination of good practices to ensure correct management of end-of-life tyres & & $\times$ & $\times$ \\
\hline \multicolumn{4}{|l|}{ 4. Other environmental aspects: reducing the ecological footprint } \\
\hline Reducing $\mathrm{CO}_{2}$ emissions & $\times$ & $x$ & $\times$ \\
\hline Environmental criteria in the use of raw material & $x$ & & \\
\hline Changes in tyre composition and/or design to reduce the tyre's unit weight and noise impact during use & $\mathrm{x}$ & & \\
\hline Environmental certifications for processes and products & $x$ & $x$ & $x$ \\
\hline
\end{tabular}

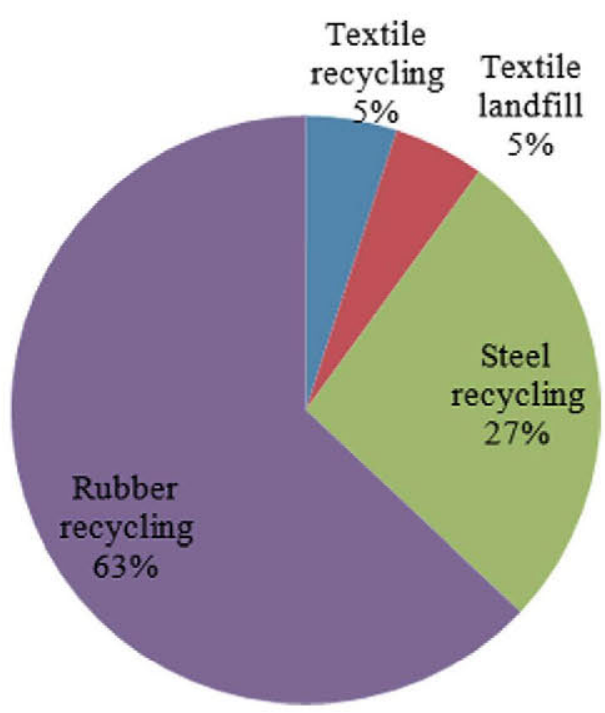

Fig. 5. Recycling market by material.

The rest were used for recycling and material recovery (51\%) and energy recovery $(40 \%)$.

In accordance with the waste hierarchy principle and to comply with the National Integrated Waste Management Plan (20082015), SIGNUS focuses on recycling and material recovery, as can be seen in the cumulative EOL tyres management data since 2006.
In parallel, the Spanish IMS continues to work to optimise management costs and processes, attempting to maintain a balance between the volume of EOL tyres and the System's recovery capacity, aside from the fact that every year the end uses sought for the tyres must be adapted to actual market circumstances. During 2010, for example, the volume of energy recovery was $10.5 \%$ greater than in the previous year.

\subsubsection{EOL tyre reuse market}

According to the waste hierarchical principle that was established in Article 4 of Directive 2008/98/EC, the reuse market is placed as the second option that deliver the best overall environmental outcome, after the Prevention Plans (which goal is to reduce the amount of waste generated).

In the Spanish market, the reuse figure ( $9 \%$ of the total managed) was maintained in 2010 . It was equal to 17,259 tonnes, slightly more than in 2009. In overall terms, since SIGNUS commenced its management activities, the reuse of used tyres on the second-hand market has remained at $9 \%$ of all tyres collected.

In regard to retreading, this is a process that allows one to reuse the tyre casing and put on a new tread, thus preserving the qualities that ensure its use as new. In Spain, retreading is almost exclusively used in truck and airplane tyres, although passenger car and industrial tyres, can also be retreaded.

There are two regulations governing retreaded tyres - (ECE Regulation 108 for private (passenger) cars and ECE Regulation 109 for commercial vehicle (Giannouli et al., 2007), that certify the quality of facilities and production processes of the retreaded tyre manu- 
facture, with similar controls and tests to those required for the approval of new tyres.

Retreading reduces raw material costs (by 30-50\%) and EOL tyres generation, and yields the same benefits as a new tyre Juniper Consultancy Services Ltd. (2004). As for drawbacks, the number of times that a tyre can be retreaded is limited, and, in some cases, its features are reduced (Krömer et al., 1999).

The economic benefits of retreading are evident in the transportation business, specifically in truck fleets. Good truck tyre maintenance allows one or two tyre retreadings and thus an overall cost reduction of tyre per kilometre. We forecast this specific market to increase slightly during the next few years in the context of the current crisis. On the other hand, passenger car tyre retreading will continue to be very limited, since new tyre budget brands are very competitive in price, leaving no benefit in for retreading.

\subsubsection{EOL tyre recycling market}

In Spain, the most typical transformation of material recycling is shredding. The cutting is performed by a shearing crusher that has two or more parallel axes blades that rotate at different speeds. The separation of the axes determines the final size. Shredding tyres facilitates their transport, reduces their volume and homogenizes the waste for use in several applications. The disadvantages are the considerable wear of the blades and the high cost of their subsequent renewal.

After the pre-shredding, grinding technologies allow to one to choose different fractions of granulation (between 2 and $4 \mathrm{~mm}$ in size is used in most applications), pulverization (between 0.8 and $2.5 \mathrm{~mm}$ for artificial grass or a base layer) and micronization (a size less than $0.8 \mathrm{~mm}$ for bitumen applications). In this field, cryogenic grinding allows one to process the shredded rubber below the freezing point of $-200^{\circ} \mathrm{C}$ so that it becomes fragile and its elasticity disappears, enabling its easily disintegration. This process begins with the use of liquid nitrogen. Then, the rubber passes through an impact mill (similar to a hammer) where it is ground. This technology facilitates rapid separation of the three components of tyres (rubber, steel and fibres) on drying (UNEP, 2000). The first cryogenic grinding operation in Spain has been installed in Valdemoro (Madrid). There is only one similar plant in Europe. It is in Germany.

Consumer markets for tyre-derived, secondary raw materials experienced a slight contraction in 2010 from the market levels of previous years. Globally, during 2010, a total of 97,214 tonnes

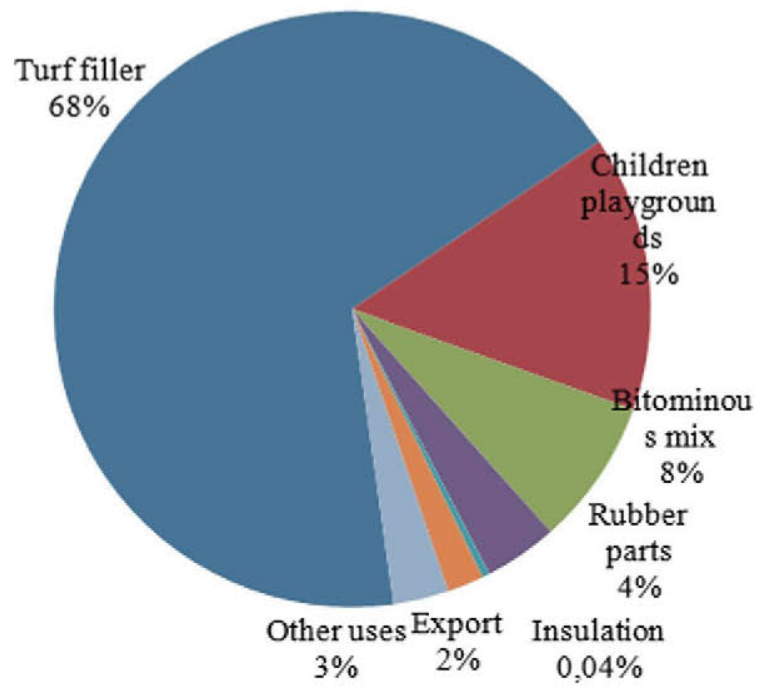

Fig. 6. Rubber granulate market. of EOL tyres were allocated by SIGNUS to material recovery, of which 2425 tonnes were used for civil engineering projects and applications while the remaining 94,788 tonnes were sent to processing facilities to extract the main tyre components by granulation.

In regard to the end uses for the materials (Fig. 5), it is important to note the increase in the percentage of recycled steel, which rose considerably over that of the previous year. The increase in outlets for the quantities that were stockpiled in facilities was due partly to the substantially higher price obtained for the raw material last year, due to the growth in demand that led to a large increase from the low average prices of the previous year. of the 21,000 tonnes of steel obtained in the management process, more than 20,000 were sent to steel plants for recycling.

Another important aspect was the significant increase in the percentage of textile used for recycling applications, instead of ending up in landfills. This improvement was due to the emergence of new applications for the product, such as the development of new types of mass concrete (SIGNUS, 2011; Aliapur, 2011).

With regard to the rubber recycling market (61,245 tonnes), rubber granulate continues to be the most important product, although the figure was down slightly from that of 2009 due to the fall in demand for the main applications. In this sense, the rubber granulate market has changed its profile slightly. Consumption for artificial turf has fallen in relative terms, and there has been, in addition, a moderate decrease in the use of granulates for the creation of children's playgrounds (Fig. 6).

Interestingly, not all end-use categories experienced a decline. Increases were seen in the quantities of materials used for rubber products and insulation, while there was a spectacular increase (2.5 times the figure of the previous year) in materials used for bituminous mixes.

\subsubsection{EOL tyre energy recovery market}

The total tonnage of EOL tyres delivered for energy recovery purposes rose to $77,597,40 \%$ of the total waste volume managed by the Spanish IMS (Table 4). The main application in this category was the use of EOL tyres as Waste Derived Fuel (WDF) in cement kilns, the industry demand for which increased dramatically.

European legislation has been adapted to permit and limit the use of EOL tyres and their emissions. EOL tyres are an alternative fuel today, but cannot exceed $20 \%$ of the total fossil fuel required in the manufacture of cement. Fuel in cement kilns accounts for $60 \%$ of EOL tyres generated in Austria. However, this drops to $38 \%, 8 \%$ and $6 \%$ in Germany, France and Britain, respectively. The clinker obtained from TDF by $20 \%$ substitution of conventional fuel is similar to that obtained using only pet coke (Trezza and Scian, 2009). To date, there are no scientific data that show a decline in the quality of the final product using this fuel.

Also noticeable in this category was 1384 tonnes of tyres that the Spanish IMS supplied to a new thermolysis facility for the first time in order to conduct a technical and economic viability study as part of its research, development and innovation programme.

Table 6

EOL Prevention Plan 2010-2013. Key indicators.

\begin{tabular}{llll}
\hline & $2008(\%)$ & $2012(\%)$ & $2015(\%)$ \\
\hline $\begin{array}{l}\text { 1. Prevention } \\
\text { Weight reduction }\end{array}$ & & & 8 \\
$\quad$ Retreading use & 98 & 15 & 20 \\
2. Recovery & & 98 & 98 \\
3. Recycling & 50 & 50 & 50 \\
Rubber & 100 & 100 & 100 \\
Steel & 30 & 25 & 20 \\
4. Energy recovery & & & \\
\hline
\end{tabular}


Table 7

Communication strategies.

\begin{tabular}{|c|c|c|}
\hline Communication strategy & Benefits & Limitations \\
\hline Annual activity reports & $\begin{array}{l}\text { Distributed to share information to all members participating in the management } \\
\text { system }\end{array}$ & Limited to this stakeholder \\
\hline Information reports & $\begin{array}{l}\text { Permits the IMS to maintain a closer relationship with the key internal } \\
\text { stakeholders }\end{array}$ & $\begin{array}{l}\text { Limited to this stakeholder, internal } \\
\text { use }\end{array}$ \\
\hline "Ecovalor" magazine & $\begin{array}{l}\text { It facilitates a constant flow of information from SIGNUS to the external } \\
\text { stakeholders and internal actors who participate in the System }\end{array}$ & \\
\hline $\begin{array}{l}\text { Advertising campaign entitled "If you do } \\
\text { not like this menu..., declare your } \\
\text { tyres" }\end{array}$ & $\begin{array}{l}\text { Its goal is to reinforce the message to producers who do not declare their tyres to } \\
\text { do so and thus ensure correct EOL tyre management }\end{array}$ & $\begin{array}{l}\text { Effectiveness depending on } \\
\text { government actions to prevent and } \\
\text { prosecute fraud }\end{array}$ \\
\hline $\begin{array}{l}\text { Regular updating of the content of the } \\
\text { SIGNUS website www.signus.es }\end{array}$ & $\begin{array}{l}\text { It keeps all of the actors involved in the IMS well informed, including end users and } \\
\text { consumers }\end{array}$ & $\begin{array}{l}\text { Relatively low awareness of the IMS in } \\
\text { the society }\end{array}$ \\
\hline $\begin{array}{l}\text { Articles and interviews in various } \\
\text { technical, tyre sector and } \\
\text { environmental journals }\end{array}$ & $\begin{array}{l}\text { Strengthen relationships with the research community and universities. Permits } \\
\text { the dissemination of knowledge }\end{array}$ & Limited to this stakeholder \\
\hline $\begin{array}{l}\text { Annual distribution of information } \\
\text { packs to all accredited ELT generation } \\
\text { locations }\end{array}$ & $\begin{array}{l}\text { It provides details of the cost of managing used tyres, together with details of the } \\
\text { management activities undertaken by the IMS. More than } 27,000 \text { sets were } \\
\text { delivered during } 2010\end{array}$ & \\
\hline
\end{tabular}

Thermolysis is the thermal degradation process of shredding or granulating tyres into intermediate substances such as gas, oil, solid residues (carbonaceous solid residue) and steel. In this process, shredded tyres $(1-3 \mathrm{~cm})$, or granulated tyres $(0.5-4 \mathrm{~mm})$ that are free of steel and textiles are heated at a moderate temperature $\left(400-800^{\circ} \mathrm{C}\right)$ in the absence of oxygen or in the presence of only a limited amount (Kalitko, 2010).

Nowadays, there are two plants in Spain that use this technology. The first has a processing capacity of 16,500 tonnes of EOL industrial use tyres per year. Its entyre process has been patented by the company "PIROREC-B\&G S.L." in collaboration with the Polytechnic University of Valencia.

The second plant is called "Grau Thermic Tyres", a prototype plant that has a capacity of 500 tonnes per year, built mainly for research by "Enreco 2000 and the CSIC State Agency" (López et al., 2011).

To date, findings from the Spanish IMS R\$D projects in this area show that thermolysis processes offer no clear advantages over other processes for the recovery of EOL tyres.

\subsection{Innovative applications}

The recovery of EOL tyres in innovative applications has been established as a key objective by IMS management. Although the current managed volumes are just anecdotal (3808 tonnes in 2010), a large growth is expected in the future. Many different uses are currently being monitored, some of which show promising results.

At a worldwide level, those applications vary from coastal protection, erosion barriers, artificial reefs, breakwaters, avalanche shelters, slope stabilisation structures, road embankments, landfill construction operations and sound barriers.

In our case, in particular, these very interesting and real examples in the form of breakwaters, crash barriers, landfill applications and embankment fill (SIGNUS, 2011) should be highlighted. All of them were developed in Spain in recent years.

\subsection{EOL tyre Prevention Plan 2010-2013}

In October 2010, the Spanish IMS presented its EOL Prevention Plan for the 2010-2013 period to the Ministry for the Environment and Rural and Marine Affairs, as required by Royal Decree 1619/ 2005. This plan must be understood to be an essential tool for compliance with the prevention of EOL tyre generation and the fostering of reduction, recycling and other forms of recovery in order to protect the environment.
Qualitatively, the more than 200 companies affiliated with SIGNUS have entrusted the company with the job of drawing up and monitoring the plan, the main objective of which is to identify the mechanisms for: (a) extending the lifespan of tyres, (b) facilitating the reuse, (c) facilitating the recycling and other forms of recovery and (d) incorporating prevention measures that can be adopted throughout the different tyre life-cycle phases (i.e., design, production, distribution and consumption), as shown in Table 5.

The companies that have signed onto the plan must implement one or more of the measures provided for during its period of validity, while SIGNUS is responsible for supervision and control.

Quantitatively, specific targets to be achieved have been set for four areas as shown in Table 6:

These indicators have specific associated measures (e.g., the increase in performance (mileage) expected from new tyre development, the percentages of specific compounds that reduce the rolling resistance, etc.) Using these indicators and measures, the Spanish IMS will collect annually all of the required information and will present the corresponding report.

In addition, with a firm commitment to successfully manage the control and follow-up phases of the plan, the IMS is carrying out (a) the recording of results of measures taken, (b) the identification of possible changes in trend resulting from new legislation in all tyre life cycle phases, as well as advances in technology and the development of new recovery markets (c) the trend analysis based on information published by prestigious environmental bodies and the rubber and tyre sectors.

In regards to the motivation of companies to adhere to this group and achieve the targets of the Plan, it should be noted that not only is there a law to observe, but also the main tyre manufacturers (and the overall tyre industry in general) have a longstanding commitment to environmental and social issues. A good example of this commitment is seen in the creation of the World Business Council for Sustainable Development (WBCSD), which is chaired by the world's three largest tyre companies (Bridgestone, Michelin and Goodyear-Dunlop).

\subsection{Communication activities}

Public awareness and communication campaigns are key issues for an environmentally sound management of wastes. The Spanish IMS has continued the progress of previous years and is constantly increasing its membership with national and international bodies, media presence and cooperation with the different actors.

The structure of this communication and advertising strategy as well as the main benefits and limitations of each tool are shown in Table 7: 


\subsection{RED projects}

Non-operational activities of the Spanish IMS include also its participation in a range of projects that are aimed principally at developing new applications for the materials obtained from EOL tyres. The most relevant one is the use of EOL tyres materials in mass concrete.

The project was completed in 2010, with funding from the Ministry of the Environment and Rural and Marine Affairs. Its main purpose was to evaluate changes in the properties of mass concrete made with materials that were obtained from EOL tyres by substituting coarse aggregate in some cases and adding materials obtained from shredding and granulation in others.

The final conclusion of this research was that the use of tyre materials in concrete may be of interest for specific applications in a number of cases where the improvements provide a competitive advantage over conventional formulations. Although the results obtained are very promising, further research needs to be conducted, especially in the fields of variance analysis and other technical aspects.

\section{Discussion}

After six years of operation, the main Spanish IMS management model has consolidated its position as a benchmark, not just in Spain, but also in other countries. During this brief period, the IMS has successfully and correctly handled almost a million tonnes of used tyres, more than $100 \%$ of the tyres placed into the market.

Nevertheless, not only the Spanish but other European IMSs are entering a new era of great challenges, defined by a difficult context of stagnant or reduced new (and consequently EOL) tyre demands (Spanish new tyre accumulated demand has decreased by $20 \%$ during the period of 2007-2010), which requires the IMSs to make innovative and efficient decisions to manage the new lower-earning scenarios.

In this sense, the collection cost of SIGNUS, which was 37.5 million $€$ and $54.4 \%$ of total costs (earnings), represents the most important area of the IMS activities Additional measures need to be taken to assure that Spanish IMS can continue to effectively attend to the more than 34,000 points of EOL tyre generation.

Thus, in a similar way to the French model, the Spanish IMS has just begun the collection tender system made possible by the electronic auctioning system. This will result in considerable savings for the IMS, but also lead to a decrease in the margins of many collectors. In addition, new collection deadlines will be implemented. These will depend on the volume generated by each outlet, with a minimum quantity of 100 passenger car tyres (or the equivalent weight) to be attended.

In regards to EOL tyre recovered products, this market has suffered greatly as a result of a lack of public spending. Indeed, one of the major consequences of certain political decisions taken by public authorities in 2010 was the paralysing of infrastructural development projects, some of which consume almost $80 \%$ of the recycled materials obtained from end-of-life tyres.

Despite the unfavourable economic global environment, the Spanish IMS is concerned with discovering and promoting new forms of recovery that, far from being tied to the mistaken and dangerous notion that the use of recycled materials should be subsidised or requires public funds, are self-supporting, enabling them to safeguard the future of the used-tyre value chain. According to our field study, Spanish IMS is currently involved in several projects on this topic and plans to continue to devote more resources to this end.

In addition, Spanish IMS has made a significant investment in the area of information systems in order to achieve better manage- ment of operational information; better support for users, clients and suppliers; and to have swift and reliable economic and financial data at the disposal of IMS. This strategic tool will contribute great credibility to the IMS model and will be the basis for the management reports that are regularly sent to the public authorities.

The intention of the Spanish IMS is to remain committed to adequate coordination between European tyre IMSs, particularly with those of its closest neighbours, in order to carry out operational benchmarking and to share a wide number of related subjects, which will enable them to implement best practices. We foresee that the creation of the Italian IMS will be similar and that it will adopt a philosophy similar to that of the French, Spanish and Portuguese models, thereby reinforcing this strategy.

We also discovered at this point that the communication strategy of the Spanish company lacks a standardised tool that would support this approach in co-operation with the IMSs, although the European Tyre and Rubber Manufacturers' Association (ETR$\mathrm{MA}$ ) is supporting the IMSs in those issues that require direct dealings with European institutions (e.g.,achieving end-of-waste status for EOL tyres).

The launch of the EOL tyres Prevention Plan 2010-2013 demonstrates the prevention commitment of companies that are affiliated with IMS and the firm intention of the company to carry forward this commitment, although responsibility for implementing the prevention measures rests ultimately with each subscribing affiliated company.

Thus, while the Plan will strengthen the implementation of prevention measures and facilitate the recognition and identification of measures already taken by firms in the sector at their own initiative, the concept of prevention needs to be reinforced in other areas in order to optimise results. With regard to recyclability, SIGNUS is making a significant effort to develop recovery markets geared to the use of rubber in bituminous mixtures for road surfacing and other industrial applications.

In regards to the role of the IMSs in this prevention area, it is interesting to note that the capacity to adopt prevention measures will be greater for manufacturers, since they establish the bases for the product and can influence matters throughout the tyre's life cycle, than for the other actors affected by the Plan such as importers, distributors and the IMSs. In any event, the firm commitment of SIGNUS in the control and follow-up phases is remarkable, apart from its overall leadership in the plan.

Lastly, the tyre industry is in a process of constant evolution. Recent years have witnessed a major effort to conceive and design increasingly environment-friendly processes and products. The measures introduced reflect the sector's commitment to the environment. The sector's long-standing commitment to prevention has led to the identification and implementation of measures with perfectly verifiable results, such as the lengthening of the life span of tyres (today's designs offer potentially greater mileage performance) and the development of increasingly specialised techniques to enable tyre reuse (regrooving and/or retreading).

These results are the outcomes of the substantial technical and economic contributions made by the stakeholders who are responsible for bringing tyres to the market. Although not a constraint, this does influence future room for manoeuvring.

\section{Conclusions}

This paper discussed how the application of the new Directive 2008/98/EC affects the Spanish IMS day-by-day operations, the issues that require further efforts to resolve, and the economic, social and environmental challenges and commitments to achieve in the short and middle term. 
About 1.4 billion tyres were sold worldwide in 2009 (JATMA, 2010). Subsequently, a large portion of this amount will fall into the category of EOL tyres in the near future. Despite the current adverse economical situation in some areas of the world, these volumes are about to increase because of the projected growing number of vehicles and increasing traffic worldwide.

In 2009 the EU27 was faced with the challenge of managing, in an environmentally sound manner, more than 3.2 million tonnes of used tyres (including tyres for retreading and reuse/export), $2.5 \%$ less than in 2008. After sorting, an estimated 2.6 million tonnes of EOL tyres remained in the EU market for recovery and recycling, 96\% correctly treated (ETRMA, 2011), which makes Europe one of the most advanced regions of the world in the recycling and recovery of these tyres.

So far, Extended Producer Responsibility (EPR) systems have shown outstanding performance in resolving EOL tyre issues in a sustainable manner for the long term, achieving in most cases a $100 \%$ recovery rate in an efficient and economical way, and in compliance with the requirements of Directive 2008/98.

In this context, the Spanish case is considered especially relevant by the authors for (a) its dimension (9\% of total EU27 EOL tyres), (b) its specific and atomised EOL tyre generation and "door to door" collection network (with 34,357 collection points in 2011 ), (c) the rapid progress made to properly manage the $100 \%$ EOL tyres and (d) the way in which the IMS proactively faces the new challenges that Directive 2008/98/EC entails.

Although the extended producer responsibility principle (Article 8) is widely established throughout Spanish territory as EOL tyre concerns, the illegal tyre importation (and undeclared) practices and uncontrolled Internet sales continue to be important issues to solve. They need a strong involvement by local authorities, not only in Spain but also in neighbouring countries.

In regards to the waste hierarchy to consider and prioritize (Article 4), the study has shown how the IMS is undertaking, a wide range of activities to find new technically and economically feasible uses for EOL tyres, especially in the category of recycling and material recovery.

Considering the area of waste prevention of the Directive and the plans and programmes to be developed by every EU Member, the Spanish IMS has developed for the first time a Prevention Plan for Companies $2010-2013$, to which $100 \%$ of their affiliated producers have signed up. In line with the Directive's requirements, the company highlights the promotion and search for innovative EOL tyre recovery applications, notably among them the hoped for and encouraging increase of $250 \%$ in the use of powder in asphalt mixes.

Remarkably, the commitment of the Spanish IMS with the external and internal stakeholders has been described in various communication activities and advertising campaigns. Commitment when implementing local waste management plans is one of the main requirements pointed out in the new Directive.

By contrasting the key new requirements of the Directive with the applied IMS management policies, future plans development and results achieved since its foundation, we can conclude that SIGNUS is pretty well aligned with the strategic vision and targets stated in the European legislation framework.

Moreover, the Spanish IMS has shown itself to be an effective instrument for managing EOL tyres. It is considered to be exemplary at international level in the way that it addresses the difficult challenge of "turning waste into a resource" as inexpensively as possible and with the fullest environmental guarantees, although the current adverse economic situation forces the company to continuously pursue new countermeasures to overcome the difficulties.

The main challenge for the mid-term future, not only for Spain, but also for the entyre European tyre industry, is to bring about the end of waste status for tyre-derived products.
Thus, the Spanish IMS is also involved in the strategic action plans developed to achieve that objective, such as the standardisation activities of EOL tyres' material quality, conducting updated life cycle assessments that demonstrate the degree of the environmental benefits of the recycling and recovery operations, etc., and showing how a recently considered scrap product can be turned into a valuable resource, with an even lower environmental impact.

In ending, it is important to emphasise the growing environmental awareness among end users, who may increasingly include this variable as a purchase criterion. This can facilitate sales of tyres that are more environmentally friendly. This situation will be encouraged by another interesting tyre development, namely the introduction of labelling that indicates the tyre's efficiency in terms of fuel consumption, noise and other parameters.

\section{Acknowledgments}

The authors especially thank Mr. J. Núñez and Mr. J.M. Bermejo (General Manager and Markets Development Manager of SIGNUS) and the reviewers for their valuable contributions to this research work. Thanks to Caja Madrid mobility grant (2011/12) that financed Professor Ponce-Cueto research activities at the MIT Center for Transportation \& Logistics.

\section{References}

Achillas, Ch., Vlachokostas, Ch., Aidonis, D., Moussiopoulos, N., lakovou, E., Banias, G., 2010. Optimising reverse logistics network to support policy-making in the case of electrical and electronic equipment. Waste Management 30 (12), 25922600.

Aiello, M.A., Leuzzi, F., Centonze, G., Maffezzoli, A., 2009. Use of steel fibres recovered from waste tyres as reinforcement in concrete: pull-out behaviour, compressive and flexural strength. Waste Management 29 (6), 1960-1970.

ALIAPUR, 2011. Activity Report 2011. Lyon, Ed. Aliapur.

Aylón, E., Fernández-Colino, A., Murillo, R., Navarro, M.V., García, T., Mastral, A.M., 2010. Valorisation of waste tyre by pyrolysis in a moving bed reactor. Waste Management 30 (7), 1220-1224

Bernardo, M., Lapa, N., Gonçalves, M., Barbosa, R., Mendes, B., Pinto, F., Gulyurtlu, I., 2010. Toxicity of char residues produced in the co-pyrolysis of different wastes. Waste Management 30 (4), 628-635.

Björklund, A.E., Finnveden, G., 2007. Life cycle assessment of a national policy proposal - the case of a Swedish waste incineration tax. Waste Management 27 (8), 1046-1058.

Donatelli, A., lovane, P., Molino, A., 2010. High energy syngas production by waste tyres steam gasification in a rotary kiln pilot plant. Experimental and numerical investigations. Fuel 89 (10), 2721-2728.

Donatello, S., Tyrer, M., Cheeseman, C.R., 2010. EU landfill waste acceptance criteria and EU Hazardous Waste Directive compliance testing of incinerated sewage sludge ash. Waste Management $30(1), 63-71$.

Economopoulos, A.P. 2010. Technoeconomic aspects of alternative municipal solid wastes treatment methods. Waste Management 30 (4), 707-715.

Eisenhardt, K.M., 1989. Building theories from case study research. Academy Management Review 14 (4), 532-550.

Ellram, L.M., 1996. The use of the case study method in logistics research. Journal of Business Logistics 17 (2), 93-138.

ETRMA, 2011. End of Life Tyres. A Valuable Resource with Growing Potential. European Tyre and Rubber Manufacturers' Association.

European Union, 2008. Directive 2008/98/EC of the European Parliament and of the Council of 19 November 2008 on Waste and Repealing Certain Directives, vol. L312, pp. 3-30.

Ferrão, P., Ribeiro, P., Silva, P., 2008. A management system for end-of-life tyres: a Portuguese case study. Waste Management 28 (3), 604-614.

Gamze Turan, N., Çoruh, S., Akdemir, A., Nuri Ergun, O., 2009. Municipal solid waste management strategies in Turkey. Waste Management 29 (1), 465-469.

Generowicz, A., Kulczycka, J., Kowalski, Z., Banach, M., 2011. Assessment of waste management technology using BATNEEC options, technology quality method and multicriteria analysis. Journal of Environmental Management 92 (4), 13141320.

Giannouli, M., de Haan, P., Keller, M., Samaras, Z., 2007. Waste from a road transport: development of a model to predict waste from end-of-life and operation phases of road vehicles in Europe. Journal of Cleaner Production 15, 1169-1182.

Grosso, M., Motta, A., Rigamonti, L., 2010. Efficiency of energy recovery from waste incineration, in the light of the new Waste Framework Directive. Waste Management 30 (7), 1238-1243.

Gunning, P.J., Hills, C.D., Carey, P.J., 2010. Accelerated carbonation treatment of industrial wastes. Waste Management 30 (6), 1081-1090. 
JATMA, 2010. Year Book. Japan Automobile Tyre Manufacturers Association.

Juniper Consultancy Services Ltd., 2004. Emerging solutions for managing scrap tyres. In: Sheppards Mill (Ed.), Technology Solutions and Market Opportunities. Gloucestershire, England, pp. 22-23.

Kalitko, V., 2010. Steam thermolysis of tyre shreds: modernization in afterburning of accompanying gas with waste steam. Journal of Engineering Physics and Thermophysics 83 (1), 179-187.

Krömer, A., Kreipe, E., Reichenbach, D., Stark, R., 1999. In: Continental, A.G. (Ed.), Life Cycle Assessment of a Car Tyre. Hannover, Germany, pp. 1-44.

Larsen, A.W., Merrill, H., Møller, J., Christensen, T.H., 2010. Waste collection systems for recyclables: an environmental and economic assessment for the municipality of Aarhus (Denmark). Waste Management 30 (5), 744-754.

López, F.A., Centeno, T.A., Alguacil, F.J., Lobate, B., 2011. Distillation of granulated scrap tires in a pilot plant. Journal Hazardous Materials 190, 285-292.

Marinković, N., Vitale, K., Janev Holcer, N., Džakula, A., Pavić, T., 2008. Management of hazardous medical waste in Croatia. Waste Management 28 (6), 1049-1056.

Milanez, B., Bührs, T., 2009. Extended producer responsibility in Brazil: the case of tyre waste. Journal of Cleaner Production 17 (6), 608-615.

PNNFU, 2001. Plan Nacional de Neumáticos Fuera de Uso, 2001-2006. Resolución de 8 de octubre de 2001, de la Secretaría General de Medio Ambiente.

Ponce-Cueto, E., González-Manteca, J.A., Carrasco-Gallego, R., 2011. Reverse logistics for used portable batteries in Spain. An analytical proposal for collecting batteries. In: Golinska, P., Fertsch, M., Marx-Gomez, J. (Eds.), Information Technologies in Environmental Engineering. New Trends and Challenges. Springer-Verlag, Berlin, pp. 593-604.
Purcell, M., Magette, W.L., 2010. Attitudes and behaviour towards waste management in the Dublin, Ireland region. Waste Management 30 (10), 1997-2006.

Sang Son, K., Hajirasouliha, I., Pilakoutas, K., 2011. Strength and deformability of waste tyre rubber-filled reinforced concrete columns. Construction and Building Materials 25 (1), 218-226.

Santini, A., Morselli, L., Passarini, F., Vassura, I., Di Carlo, S., Bonino, F., 2011. End-ofLife Vehicles management: Italian material and energy recovery efficiency. Waste Management 31 (3), 489-494.

Secretariat of Basel Convention, 2000. Technical guidelines for the identification and management of used tyres. United Nations Environment Programme (UNEP), pp. 1-47.

Shulman, V.L., 2011. Tyre Recycling. Waste, pp. 297-320.

SIGNUS, 2010. Annual Report. Madrid: Ed. Signus.

SIGNUS, 2011. Annual Report. Madrid: Ed. Signus.

Singh, S., Nimmo, W., Gibbs, B.M., Williams, P.T., 2009. Waste tyre rubber as a secondary fuel for power plants. Fuel 88 (12), 2473-2480.

Spicer, A.J., Johnson, M.R., 2004. Third-party demanufacturing as a solution for extended producer responsibility. Journal of Cleaner Production 12, 37-45.

Trezza, M.A., Scian, A.N., 2009. Scrap tire ashes in portland cement production. Materials Research 12 (4), 489-494.

WBCSD, 2010. End of Life Tires. A Framework for Effective Management Systems. World Business Council for Sustainable Development. 